\title{
Paralonde!?

\section{O ENCANTAMENTO DO ESPAÇO MENTALMENTE PROJETADO: UM CONCEITO PARA O ENSINO DA GEOGRAFIA ESCOLAR}

The encouragement of mentally designed space: a concept for the teaching of school geography

Leonardo Pinto dos Santos*

Eduardo Schiavone Cardoso**

*Professor da rede estadual de ensino do RS e doutorando do PPG em Geografia - UFSM - leonardoufsm@hotmail.com. **Docente do PPG em Geografia - UFSM - educard@smail.ufsm.br.

Recebido em 05/08/2018. Aceito para publicação em 20/08/2018.

Versão online publicada em 03/09/2018 (http://seer.ufrgs.br/paraonde)

\begin{abstract}
Resumo:
0 presente artigo é fruto de uma pesquisa em andamento através do programa de pós-graduação em Geografia da Universidade Federal de Santa Maria (UFSM), cujo objetivo é pensar a Geografia Escolar a partir do conceito de Espaço Mentalmente Projetado (EMP). Este é um conceito pensado para o ensino da Geografia na educação básica, em que o estudante por meio da ação passa a construir mentalmente espaços por ele não vivenciado de forma direta, sendo capaz de projetar este espaço que habita seu imagético.
\end{abstract}

Palavras-chave: Ensino de Geografia; EMP; Epistemologia Genética.

\begin{abstract}
:
This article is the result of a research in progress through the Postgraduate course in Geography of the Universidade Federal de Santa Maria (UFSM), whose objective is to think of School Geography from the concept of Mentally Designed Space (EMP). This is a concept thought for the teaching of Geography in basic education, in which the student through the action begins to mentally construct spaces that he does not directly experience, being able to project this space that inhabits his mind.
\end{abstract}

Key-words: Geography Teaching; EMP; Genetic Epistemology.

\section{Introdução}

Há um mundo dentro de nós, dentro de nossa mente, neste órgão que é o mais sensacional e de maior mistério nessa máquina chamada corpo humano. Esse "mundo mental" vale a pena ser descoberto, principalmente quando vamos para o campo do ensino.

Temos plena consciência que "nenhum aspecto da mente humana é fácil de investigar" (DAMÁSIO, 2000, p.18), mas o que é mais curioso e até mesmo divertido do que tentar compreender os mistérios da consciência de nossos estudantes?

Assim, nosso trabalho é um convite a contemplação da imaginação dos nossos alunos, ou melhor, da projeção mental que estes fazem do espaço geográfico. 
Essa construção imagética do espaço geográfico parte das experiências vividas, sentidas e pensadas por parte do sujeito, que ao brincar com as ideias de mundo acaba por produzir complexos universos simbólicos com diferentes concepções de mundo.

Nosso mundo (experenciado e simbólico) é um tecido de encontros e desencontros, de ganhos e perdas, sendo ingenuidade nossa - como seres pensantes - acreditar em um Brasil, em uma Argentina, em uma Nigéria ou França representada em cartões postais. Se o mundo não é um cartão postal, ou seja, um mundo parado no tempo, onde há muita luz e beleza e pouco da realidade, que mundo seria este que habitamos? Que espaço geográfico é este que nossos estudantes constroem em sua vivência (tanto cotidianas, bem como simbólicas/imagéticas)?

Muito de nossa Geografia - enquanto professores e alunos - é simbólica, pois trabalhamos com espaços que estão distantes de nossa percepção imediata. Portanto, nossas Geografias precisam ser pensadas e trabalhadas a partir dos significantes e significados, dos signos, ou melhor, a partir de nossa própria imaginação, uma vez que, "a imaginação voa imediatamente no espaço" (DURAND, 2012, p.398).

Construir a legibilidade de mundos através de várias possibilidades de representação é a nossa busca ao trabalhar com o conceito de Espaço Mentalmente Projetado (COSTELLA, 2008; SANTOS, 2015; 2017; SANTOS; MENEZES; COSTELLA, 2018).

Espaço Mentalmente Projetado é um termo utilizado pela teoria que compreende a forma ou a maneira como o aluno, sujeito da análise, pode enxergar um espaço que está em sua mente, no seu imagético, por meio de ações e coordenações de ações diante de conceitos que compreendem um espaço ausente concretamente, mas presente em sua capacidade de projetar (COSTELLA, 2008, p.38).

Ele é um conceito voltado para a Geografia Escolar que nos leva a pensar de que forma o estudante representa espaços que por diversas vezes permanecem no nível conceitual. 0 indivíduo a partir de sua progressiva maturação e interação com os objetos passa a ter a competência de projetar estes espaços que estão em seu imagético, sendo conhecedor deste (SANTOS, 2017, p.42).

Pare um pouco e reflita querido(a) leitor(a): você já parou para pensar que o espaço geográfico que você e seus amigos e familiares habitam, carrega muito de um teor simbólico que o faz existir. Não lhe parece que passamos a fixar em um suporte imagético uma série de sensações e experiências que fazem nascer para nós uma África, uma América Latina, uma região Sul ou Nordeste?

Não existe, por exemplo, um sabor ou um cheiro que lhe desperte uma lembrança? Aquele cheiro de chuva a pouco precipitada, o pão de queijo saído do forno na casa dos avós, o som marcante do canto do quero-quero, o perfume das rosas floridas, o colorido de uma fotografia antiga, o estampido da gordura da carne caindo no fogo no churrasco de domingo ou a música de rua nos passeios no parque com a pessoa amada. Todos temos lembranças que nos transportam a lugares de nossa infância, lugares construídos em nosso cognitivo.

Se estes espaços que em algum momento foram experenciados por nós estão construídos, de uma forma simbólica que seja, o que dizer dos lugares distantes que talvez nunca cheguemos a conhecer de forma direta, seja como turistas ou residentes locais. Quando você professor ou professora prepara suas aulas sobre a América Latina ou Oceania, você não passa a pensar e refletir sobre estes espaços? Você não passa a construí-los em seu imagético, mesmo que não o tenha vivenciado?

E os nossos alunos e alunas, não passam a "vivenciar" estes lugares quando você trabalha os conteúdos com eles? Ou quando acessam notícias sobre a crise da Venezuela ou o artista morto por overdose em uma fase da vida que não deveríamos deixar de viver, ou quando eclode um conflito armado em um país africano que já foi por demais degastado por interesses internacionais ou mesmo 
quando um grupo de meninas é sequestrado da escola para viverem sobre o regime abusivo de extremistas religiosos, ou quando centenas de crianças morrem afogadas na travessia do Mediterrâneo junto a seus pais que como sonho apenas desejam viver em paz com seus pares seres humanos.

Ao "vivenciá-los" pela mídia, no contato com os professores e amigos, pela literatura ou na música, eles não constroem um espaço geográfico?

Acreditamos que sim, mas de que forma isso ocorre? Que espaço geográfico é este? Serão os mundos representados pelos cartões postais? Pelas imagens vinculadas nas redes sociais? Será uma construção caricata e estereotipada? Terá alguma relação com a realidade que se apresenta nestes lugares?

Que Espaço Mentalmente Projetado é este e de que forma podemos, enquanto professores, construir junto aos jovens, uma visão com menos ruídos, com menos distorções da realidade, este é o nosso anseio com esta tese de doutorado que se encontra em fase de desenvolvimento na Universidade Federal de Santa Maria (UFSM) no Rio Grande do Sul.

\section{Desenvolvimento}

Durante a pesquisa se buscará o desejo de estabelecer interlocução entre três autores (Piaget (1971; 1978; 1995; 2005; 2012); Piaget; Inhelder (1956; 1976); Montessori $(1965 ; 1971 ; 1972)$; Moscovici (2011)) que, usualmente, se situam em diferentes campos do conhecimento, que ao mesmo tempo se diferenciam e se complementam.

Nosso intuito não é nem acirrar nem borrar fronteiras, mas sim apontar possíveis intersecções na compreensão do conhecimento geográfico de nossos estudantes. De forma mais marcante, o conhecimento geográfico que tangencia os "espaços ausentes", ou seja, aqueles não cotidianos aos nossos discentes.

Como objetivo de nosso trabalho, temos: pensar o conceito do Espaço Mentalmente Projetado no ensino da Geografia Escolar e estabelecer uma ligação entre a concepção de espaço de Jean Piaget para com o espaço geográfico, objeto de estudo de nossa ciência.

Como o senso comum nos fala, existe um método para essa nossa loucura. Nossa escolha é pela Fenomenologia (MERLEAU-PONTY, 2011).

Essa definição parte do tipo de trabalho que desenvolveremos, onde o nosso pensar caminha no ideário de que a realidade não é única. 0 sujeito aluno é reconhecido no processo de construção do conhecimento e compreendemos a Fenomenologia como o estudo da consciência e dos objetos da consciência, ela nos passa a ideia de fluidez e de intencionalidade, o que necessitamos para pensar o Espaço Mentalmente Projetado.

É importante ressaltar que "o método não deve ser visto como algo estático e cristalizado; não deve ser uma camisa-de-força para o pesquisador" (MORAES; COSTA, 1999, p.30), é um erro da Geografia e da Ciência - principalmente nas humanidades -, desejar um modelo que se encaixe perfeitamente, que se encontre pronto na prateleira esperando que alguém o pegue e o utilize.

Por trabalhar com o conceito de Espaço Mentalmente Projetado, pesquisamos a intencionalidade que o sujeito produz sobre os objetos do conhecimento, intencionalidades estas forjadas a partir da experiência que estes mesmos sujeitos vivenciaram (SANTOS, 2015). Isso faz com que a Fenomenologia se configure como o melhor estuário para o início de nossa navegação em busca da mente (representações) de nossos alunos e alunas.

O fio narrativo que circula e produz sentido não é um único fio, mas três que como uma bacia hidrográfica possui o canal principal e vários afluentes que o alimentam. No nosso caso temos três rios principais que se comunicam: Jean Piaget, com sua Epistemologia Genética, Maria Montessori, 
com sua Educação pelos Sentidos e Serge Moscovici, com sua teoria das Representações Sociais.

Como na hierarquia fluvial existem os tributários do rio principal, nossa tese também trabalha com os conceitos que servem como tributários para a busca dos nossos objetivos, são eles: os conceitos de Paisagem e Espaço (Gomes, 2013; Massey, 2013; Tuan, 2013).

0 nosso trabalho pode ser resumido por um dos quadros mais famosos do mundo: Mona Lisa de Leonardo Da Vinci. O seu sorriso instigante é como a mente dos nossos alunos, por muito tempo pessoas investigaram e criaram lendas entorno dos mistérios que penduram sobre o quadro do pintor italiano. 0 quadro e seus mistérios permanecem, bem como, o pleno funcionamento do cérebro ainda é algo estranho ao conhecimento de nossa humanidade.

É este órgão ainda não compreendido em sua plenitude que as estruturas cognitivas são formadas, em que as representações e o espaço são construídos, é aqui que o simbólico pode se tornar realidade, onde a razão e a emoção parecem conviver em harmonia sobre um mesmo "teto", é nesta parte de nosso corpo que as nossas Geografias são estruturadas e por onde a humanidade conseguiu progredir de uma espécie frágil ao "topo da cadeia alimentar". "O cérebro é um corpo inteiro, é um organismo inteiro e é mais do que um organismo inteiro. Um cérebro são todos os organismos possíveis de serem por ele imaginado" (GIL, 2011, p.184).

O que nosso cérebro constrói passa a se tornar real para nós, sejamos professores ou alunos, voltemos ao exemplo de Mona Lisa: imagine que você leitor ou leitora vai visitar Paris na França e dizemos a você para ir ver o quadro no Museu do Louvre.

No caminho para percorrer os corredores do Louvre até a obra de Leonardo Da Vinci falaremos a você sobre a pintura, você nunca viu a pintura in loco (somente possui a representação coletiva sobre o objeto), então caminhamos até ela e continuamos debatendo sobre ela nos seus mais ínfimos detalhes.

Até que você chegue perto do quadro e olhe diretamente para ele, estará produzindo uma determinada representação, uma certa intencionalidade sobre aquele objeto, essa representaçãointencionalidade poderá se confirmar ou mesmo de surpreender de forma positiva ou até mesmo negativamente.

Isso é o que decorre com os Espaços Mentalmente Projetados que estudamos na Geografia, o continente latino-americano, por exemplo, é carregado de intencionalidades por sua parte (e por parte do livro didático, pela notícia vinculada ao jornal, etc.) ao ponto que visitar o continente poderá levar seu imaginário a ser preenchido com as relações que pensava existir ou sofrer de um assombro por aquilo que está posto a sua frente.

Por isso se torna importante para a Geografia Escolar pensar de que forma nossos estudantes estão construindo estes espaços geográficos, mas que não são os nossos espaços cotidianos e de que modo podemos trabalhar de forma cooperativa para que o Brasil seja visto pelo prisma dos brasis, que o mundo seja mundos, que a sociedade humana não seja monocromática, e sim, um arco-íris de culturas, sotaques, odores e ritmos.

Assim, desenhamos práticas com o intuito de trabalhar com a descentração (Piaget (1995); Montessori (1971)) do sujeito, envolvendo músicas, aromas e sabores, escritas de cartas e literatura, estamos desejosos que os sujeitos da pesquisa (estudantes da rede pública de ensino dos oitavos e nonos anos) passem a pensar sobre o ver um mundo de outra perspectiva, o que nos aproxima de identidades e pluralidades de um espaço geográfico que deve ser visto e compreendido, como bem colocado por Piaget (1978, p.389) "a inteligência é construção de relações e não apenas identificação", o que e qual o objetivo da ciência geográfica?

Desta forma, pensamos em práticas que envolvem ao mesmo tempo aspectos figurativos e operatórios do pensamento humano, tendo como preocupação central o Espaço Mentalmente Projetado, buscando-se uma "memória afetiva" na construção teórica destes espaços geográficos. 


\section{Considerações Finais}

A ciência geográfica carrega em sua essência o campo dos símbolos, a possibilidade de imaginar e de (re)significar, isto é o que faz desta ciência ser tão encantadora para nós professores e para nossos estudantes.

Para que ela permaneça encantando é necessário refletir sobre nossas práticas quando nos referimos a estes espaços ausentes que coexistem e se modificam constantemente, portanto, o conceito de Espaço Mentalmente Projetado se contorna de importância, uma vez que, foca nos processos mentais que os sujeitos epistêmicos desenvolvem para construir espaços geográficos que são compostos de realidades e não de uma única e solitária realidade.

Um ensino que se paute na enumeração e em meras descrições áridas destas realidades irá compor um desserviço as mentes juvenis que dialogam conosco, pensando no EMP e em um ensino configurado a partir da interação do indivíduo, faremos com que seja possível pensar em uma sociedade mais igualitária entre tantos sujeitos que carregam consigo experiências de vida e saberes ricos para se ver e pensar a Geografia.

Castro (1957, p.11) nos fala que a Geografia já foi um simples catálogo enumerativo dos lugares, mas as transformações fizeram dela uma ciência complexa que ao chegar na escola básica precisa ser constentemente reprensada com o intuito de se ver/perceber o espaço geográfico.

Não há disciplina científica cujo conceito tenha variado tanto através dos tempos como a Geografia, apesar de ter sempre um mesmo campo de estudo - a superfície da terra. Simples catálogo enumerativo dos lugares, na antiguidade; traçado de itinerários das terras conquistadas, no tempo dos romanos; espelho mágico do mundo na era das grandes descobertas, a geografia tornou-se hoje uma ciência complexa, a mais enciclopédica e universalista das ciências.

Desta forma, essa pesquisa busca dar voz aos estudantes, visto como seres ativos na construção do conhecimento geográfico. A partir de suas produções teremos um cabedal teórico que balizará o nosso pensar sobre novas possibilidades em relação as práticas que ajudem os nossos/vossos estudantes em distintas realidades brasileiras, pensando sempre na formação de uma realidade que se respeite a diversidade que não somente formou o povo brasileiro, mas o mundo como um todo, compreendendo desta forma essa ciência complexa que se tornou a nossa Geografia.

Com o trabalho que se encontra em andamento, o foco será compreender os caminhos a percorrer para o entendimento de Espaços Mentalmente Projetados, trabalhando com o sujeito aluno como epicentro do processo de construção do conhecimento, visando documentar a ação criadora destes em suas coordenações de ações referentes a leitura de mundo.

Este sofrerá constantes desequilíbrios para buscar a auto-regulação de seu organismo que tende a entrar em infinitos processos de equilibração, fazendo com que neste jogo simbólico de busca ele mesmo tome consciência das possibilidades que o Espaço Geográfico emana, vendo a sociedade humana como plural em sua essência.

Das práticas pedagógicas pensadas, se produzirá diversas representações que servirão de base para essa "tomada de consciência" por parte do indivíduo, sendo relacionada as produções dos estudantes com o escopo teórico piagetiano e montessoriano, com o intuito de aprofundar relações e minimizar os pré-conceitos de Espaços Geográficos que em um pêndulo carrega diversidades ao mesmo passo que se tenta vender uma imagem de "aldeia global" que tende a processos homogeneizantes.

Em seu discurso proferido em Estocolmo quando agraciado pelo Prêmio Nobel de Literatura de 2010, Mario Vargas Llosa (2015, p.15) fala: 


\begin{abstract}
Aprendi a ler aos cinco anos, na turma do irmão Justiniano, no Colégio de la Salle, em Cochabamba, na Bolívia. Foi a coisa mais importante que me aconteceu na vida. Quase setenta anos depois, lembro claramente de como a magia de traduzir as palavras dos livros em imagens enriqueceu minha vida, quebrando as barreiras do tempo e do espaço e me permitindo viajar mil léguas submarinas com o capitão Nemo, lutar com d'Artagnam, Athos, Portos e Aramis, contra as intrigas ameaçando a rainha nos tempos do misterioso cardeal Richelieu, ou me arrastar pelos esgotos de Paris, transformado em Jean Valjean com o corpo inerte de Marius às costas.
\end{abstract}

Nesta fala do escritor peruano, fica evidente a importância do ato de ler na vida de qualquer pessoa. A possibilidade de significar os símbolos presente nos livros acaba por nos permitir quebrar as barreiras que nos prendem ao concreto, nos levando em direção ao ausente presente no espaço, fazendo com que viajemos sobre as mil léguas submarinas ou adentremos aos esgotos de Paris, sendo que o estudo do Espaço Mentalmente Projetado almeja essa quebra de limites espaciais com o intuito de se fortalecer a leitura de mundo, acreditando sempre que quem compreende a Geografia jamais volta a ver o Espaço Geográfico com os mesmos olhos.

\title{
4. Referências
}

CASTRO, Josué de. Ensaios de Geografia Humana. São Paulo: Editora Brasiliense, 1957.

COSTELLA, Roselane Zordan. O significado da construção do conhecimento geográfico gerado por vivências e por representações espaciais. 2008. 202 f. Tese (Doutorado em Geografia) - Universidade Federal do Rio Grande do Sul, Porto Alegre, 2008.

DAMÁSIO, António Rosa. O mistério da consciência: do corpo e das emoções ao conhecimento de si. tradução Laura Teixeira Motta. São Paulo: Companhia das Letras, 2000.

DURAND, Gilbert. As estruturas antropológicas do imaginário: introdução à arquetipologia geral. tradução Hélder Godinho. 4. ed. São Paulo: Editora WMF Martins Fontes, 2012.

GIL, Gilberto. Arte, cultura e ciência. In: HISSA, Cássio Eduardo Viana (Org.). Conversações de artes e de ciências. Belo Horizonte: Editora UFMG, 2011. p.177-195.

GOMES, Paulo Cesar da Costa. O lugar do olhar: elementos para uma geografia da visibilidade. Rio de Janeiro: Bertrand Brasil, 2013.

LLOSA, Mario Vargas. Elogio da leitura. tradução Larry Fernandes. São Paulo: Editora Simonsen, 2015.

MASSEY, Doreen. Pelo espaço: uma nova política da espacialidade. tradução Hilda Pareto Maciel e Rogério Haesbaert. 4. ed. Rio de Janeiro: Bertrand Brasil, 2013.

MERLEAU-PONTY, Maurice. Fenomenologia da percepção. tradução Carlos Alberto Ribeiro de Moura. 4. ed. São Paulo: WMF Martins Fontes, 2011.

MONTESSORI, Maria. Pedagogia Científica: a descoberta da criança. tradução de Aury Azélio Brunetti. São Paulo: Livraria Editora Flamboyant, 1965.

. A mente da criança: mente absorvente. tradução de Pedro da Silveira. Rio de Janeiro: Portugália Editora, 1971.

. A criança. tradução Adília Ribeiro. 5. ed. Rio de Janeiro: Portugália Editora, 1972.

MORAES, Antonio Carlos Robert; COSTA, Wanderley Messias da. Geografia crítica: a valorização do espaço. 4. ed. São Paulo: Editora HUCITEC, 1999.

MOSCOVICI, Serge. Representações sociais: investigação em psicologia social. 8. ed. tradução Pedrinho 
Arcides Guareschi. Rio de Janeiro: Vozes, 2011.

PIAGET, Jean. La epistemología del espacio. Buenos Aires: Librería “El Ateneo” Editorial, 1971.

O nascimento da inteligência na criança. 3. ed. Rio de Janeiro: Zahar, 1978.

Abstração reflexionante: relações lógico-aritméticas e ordem das relações espaciais. Porto Alegre: Artmed, 1995.

A representação do mundo na criança: com o concurso de onze colaboradores. tradução Adail Ubirajara Sobral e Maria Stela Gonçalves. 2. ed. São Paulo: Idéias \& Letras, 2005. 2012.

Epistemologia genética. tradução Álvaro Cabral. 4. ed. São Paulo: Editora WMF Martins Fontes,

PIAGET, Jean; INHELDER, Bärbel. The child's conception of space. tradução F. J. Langdon; J. L. Lunzer. Londres: Routledge \& Kegan Paul, 1956.

Da lógica da criança à lógica do adolescente: ensaio sobre a construção das estruturas operatórias formais. tradução Dante Moreira Leite. São Paulo: Pioneira, 1976.

SANTOS, Leonardo Pinto dos. A construção das relações do espaço ausente na Geografia escolar. 2015. 196 f. Dissertação (Mestrado em Geografia) - Instituto de Geociências, UFRGS, 2015.

A Geografia Escolar: o Espaço Mentalmente Projetado (EMP), a criança e o pensamento formal - uma breve introdução. In: OLIVEIRA, Tarcicio Dorn de (Org.). Educação, espaço construído e tecnologias: reflexões, desafios e perspectivas. Curitiba: Editora CRV, 2017. 3.v. p.37-51.

SANTOS, Leonardo Pinto dos; MENEZES, Victória Sabbado; COSTELLA, Roselane Zordan. Piaget pedagogo? A criança, o espaço geográfico e a epistemologia do professor. In: Itinerarius Reflectionis, Jataí, v.14, n.2, p.01-18, $2018 . \quad$ Disponível em: <https://www.revistas.ufg.br/rir/article/view/51727>. Acesso em: 17 de jul. 2018.

TUAN, Yi-Fu. Espaço e lugar: a perspectiva da experiência. tradução Lívia de Oliveira. Londrina: Eduel, 2013. 